\title{
Is correction of segmental kyphosis necessary in single-level anterior cervical fusion surgery? An observational study
}

This article was published in the following Dove Press journal:

Therapeutics and Clinical Risk Management

\author{
Jian $\mathrm{Lu}^{\mathrm{l}, *}$ \\ Changjun Sun ${ }^{2, *}$ \\ Jiangbo Bai ${ }^{1, *}$ \\ Siyu Tian ${ }^{1, *}$ \\ Bing Zhang' \\ Dehu Tian' \\ Lingde Kong'
}

'Department of Orthopedics, The Third Hospital of Hebei Medical University, Shijiazhuang, Hebei 05005 I, China; ${ }^{2}$ Department of Emergency,

The Second Hospital of Tangshan City, Tangshan, Hebei 063000, China

*These authors contributed equally to this work
Correspondence: Lingde Kong Department of Orthopedics, The Third Hospital of Hebei Medical University, 139 Ziqiang Road, Shijiazhuang,

Hebei 05005I, China

Tel +86 I50 32। I I 276

Fax +86 3II 88602007

Email sdghgk@I26.com
Background: This study was conducted to determine whether sagittal lordotic alignment and clinical outcomes could be improved by the correction of segmental kyphosis after single-level anterior cervical discectomy and fusion (ACDF) surgery.

Patients and methods: We retrospectively reviewed patients who underwent single-level ACDF surgery in our hospital between January 2014 and February 2017. Basic characteristics of patients included age at surgery, gender, diagnosis, duration of symptoms, and location of target level. Pre- and postoperative radiographs at the 6-month follow-up were used to evaluate the following parameters, such as segmental angle, C2-C7 angle, T1 slope, and C2-C7 sagittal vertical axis (SVA). Postoperative clinical outcomes were assessed by the Neck Disability Index and VAS. According to the segmental angle of postoperative radiographs, patients were divided into noncorrection group and correction group.

Results: A total of 181 patients (99 males and 82 females) were analyzed in our study. There were 32 patients in the noncorrection group and 149 patients in the correction group. There was no significant difference in demographic and clinical data between the two groups before surgery. However, patients in the correction group showed larger $\mathrm{C} 2-\mathrm{C} 7$ angle and lower $\mathrm{C} 2-\mathrm{C} 7$ SVA after surgery in comparison with those in the noncorrection group. Besides, changes in the segmental angle were positively correlated with changes in $\mathrm{C} 2-\mathrm{C} 7$ angle and negatively correlated with changes in C2-C7 SVA.

Conclusion: Surgical correction of segmental kyphosis in single-level cervical surgery contributed to balanced cervical alignment in comparison with those without satisfactory correction. However, we could not demonstrate that the correction of segmental alignment is associated with a better recovery in clinical outcomes.

Keywords: segmental kyphosis, sagittal alignment, single level, cervical spine, anterior cervical discectomy and fusion

\section{Background}

Cervical degenerative disease is one of the most common causes of spinal dysfunction worldwide, which can be debilitating to patients, causing neck pain, limb pain, and numbness. ${ }^{1,2}$ In patients with degenerative disease, cervical segmental kyphosis is commonly seen because of the loss of disc height. In the past decades, anterior cervical discectomy and fusion (ACDF) has become the gold standard procedure for the operative treatment of degenerative cervical disc disease associated with radiculopathy or myelopathy. ${ }^{3,4}$ The anterior approach is particularly effective for the direct removal of anterior bony spurs and disc fragments, restoration of intervertebral height, and correction of segmental deformities. ${ }^{5,6}$ 
In comparison with lumbar sagittal alignment, which has received a large amount of attention from other authors, ${ }^{7}$ much less is known regarding the relationship of cervical sagittal alignment and clinical outcomes. Some researchers think that the degree of cervical lordosis is important in achieving good outcomes and postoperative kyphosis would deteriorate long-term function. For example, $\mathrm{Wu}$ et $\mathrm{al}^{8}$ conducted a study investigating the correlation of change in sagittal alignment and clinical outcomes and concluded that cervical lordosis improvement does affect the long-term results of anterior cervical fusion. Hyun et $\mathrm{al}^{9}$ investigated patients who underwent multilevel posterior cervical fusion and found that the disability of the neck increased with progressive cervical sagittal malalignment.

Although it is demonstrated that the physiological sagittal balance is important for normal function of the spine, whether maintenance and improvement of cervical segmental lordosis have an effect on good sagittal alignment and satisfactory clinical outcomes after cervical spine surgeries remains to be proven. This study included patients with segmental kyphosis and tried to determine whether sagittal lordotic alignment and clinical outcomes could be improved by the correction of segmental kyphosis after single-level ACDF surgery.

\section{Patients and methods Patient population}

We retrospectively reviewed patients who underwent singlelevel ACDF surgery in our hospital between January 2014 and February 2017. The inclusion criteria were adult patients with radiculopathy or myelopathy caused by single-level cervical degenerative disc disease and showing segmental lordosis in radiographic images. In addition, only those involving C4-C7 were included. Patients with tumor, infection, deformity, trauma, or prior cervical spinal surgery were excluded. Patients with any nonfusion surgery, such as total disc replacement, were also excluded. The ethics committee of the Third Hospital of Hebei Medical University approved this research, and written informed consents were acquired from these patients. All procedures performed in this study complied with the requirements of the Declaration of Helsinki.

\section{Treatment and follow-up}

Before surgery, anteroposterior, lateral, and flexion/extension lateral X-ray tests and magnetic resonance imaging (MRI) scans were performed in patients. All patients underwent ACDF procedures. ${ }^{10}$ After general anesthesia, the patient was placed supine with mild cervical extension. A standard right-sided approach through a transverse incision was used to expose the targeted segment. Then, the compressive materials were removed, which included herniated disc, osteophytes, and the posterior longitudinal ligament. After that, polyetheretherketone cage filled with excised osteophytes was inserted between vertebral bodies, and then the plate was fixed with screws inserted cranially and caudally. A soft collar was used for 6 weeks postoperatively.

All surgeries were performed by the same surgeon. Routine X-ray tests were performed postoperatively at 3, 6, and 12 months and then annually. Patients underwent X-ray test in neutral standing position and were instructed to look straight ahead, with hips and knees extended.

\section{Parameter evaluation}

Basic characteristics of patients included age at surgery, gender, diagnosis, duration of symptoms, and location of target level. Postoperative radiographs at the 6-month follow-up were used to evaluate the following parameters, such as segmental angle, C2-C7 angle, T1 slope, and C2-C7 sagittal vertical axis (SVA). Postoperative clinical outcomes were assessed by Neck Disability Index (NDI) and VAS at 6 months after surgery. The NDI was used to evaluate chronic disability and activities of daily living, which consists of 10 questions. ${ }^{11}$ The total NDI score can vary between 0 and 50, and the best outcome will be a total score of 0 . The severity of neck and arm pain was evaluated using VAS, with 0 representing no pain and 10 representing maximum pain.

The following parameters were evaluated. In brief, segmental angle of fused vertebrae was measured as superior endplate of cranial vertebral body and inferior endplate of caudal vertebral body in the index level; C2-C7 angle was formed by the inferior endplates of $\mathrm{C} 2$ and $\mathrm{C} 7$ in standing lateral radiographs; T1 slope was defined as the angle between a horizontal line and the superior endplate of $\mathrm{T} 1$; and C2-C7 SVA was the distance between the C2 plumb line and the posterior superior endplate of $\mathrm{C} 7 .{ }^{12}$ The changes in radiographic parameters were calculated as the postoperative value minus the preoperative one.

According to the segmental angle of postoperative radiographs, the patients were divided into two groups. Patients with kyphosis segment angle $\left(\leq 0^{\circ}\right)$ after surgery were categorized as the noncorrection group, and the other patients with lordosis segmental angle $\left(>0^{\circ}\right)$ were categorized as the correction group (Figure 1). Two blinded observers assessed the radiological findings independently, and the mean values were used.

We defined degenerative changes in adjacent discs according to a six-level grading system. ${ }^{13}$ The grade of 

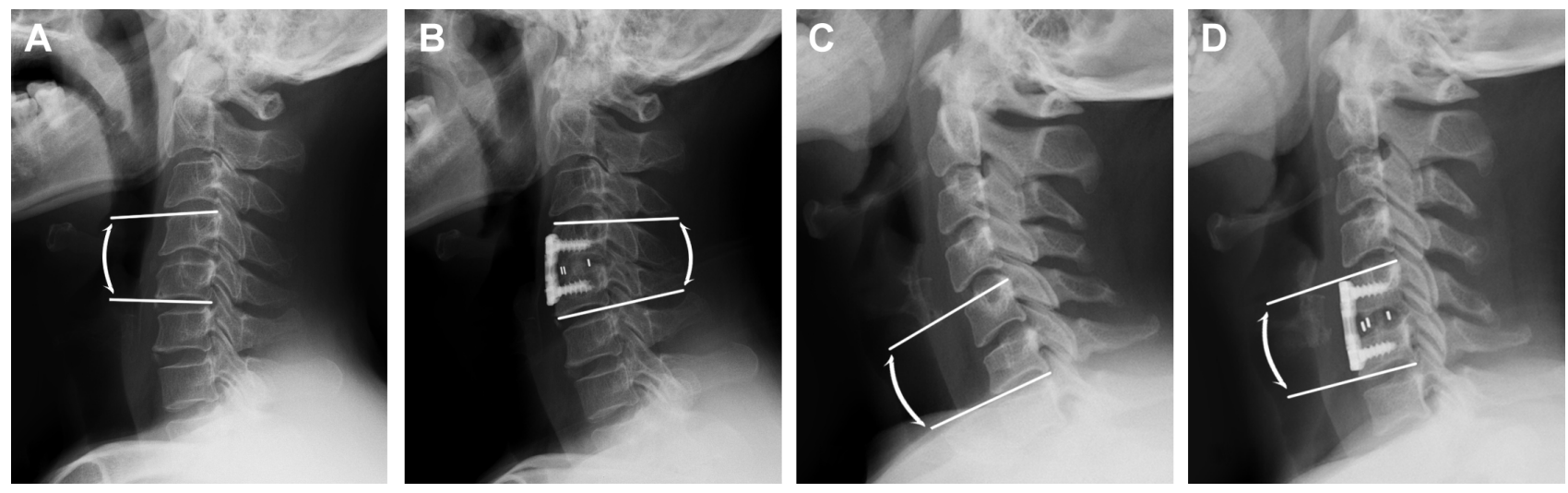

Figure I Lateral X-ray pictures showing changes in segmental angle.

Notes: (A and B) Pre- and postoperative segment angles of a patient in the correction group, respectively, and (C and $\mathbf{D})$ pre- and postoperative segment angles of a patient in the noncorrection group, respectively.

degenerative changes was determined for both the superior and the inferior adjacent levels and assessed preoperatively and at the 6-month follow-up examination. Radiographic fusion observations were graded according to the criteria summarized by Brantigan, ${ }^{14}$ and fusion results were categorized as radiographic fusion, fusion status uncertain, and radiographic pseudarthrosis.

\section{Statistical analyses}

The statistical analyses were performed with the SPSS, Version 18.0 (IBM Corp., Armonk, NY, USA). Variables were presented as mean with SD for continuous variables and with frequencies and percentages for categorical variables. The independent sample $t$ test or Mann-Whitney $U$ test was used for numerical data. The parametric tests will be applied when normality (and homogeneity of variance) assumptions are satisfied, otherwise the equivalent nonparametric test will be used. The Fisher's exact test was used to identify differences in the frequency of nominal variables between groups. $P$-values $<0.05$ were regarded as statistically significant. Pearson correlation analyses were used to evaluate the relationship of the change in segmental angle with the change in C2-C7 angle as well as C2-C7 SVA. The intraobserver reproducibility and interobserver reliability were calculated using the reliability statistics of interclass correlation (ICC) for the radiographic parameters. ICCs $<0.40$ indicate poor reliability, ICCs ranging from 0.40 to 0.75 indicate fair or good reliability, and ICCs ranging from 0.75 to 1.00 indicate excellent reliability.

\section{Results}

A total of 181 patients (99 males and 82 females) with singlelevel cervical degenerative disc disease were analyzed in our study. The mean age of these patients were $49.3 \pm 10.2$ years.
Among them, 124 (68.5\%) patients had radiculopathy and the other 57 (31.5\%) patients had myelopathy. The duration of symptoms was $23.7 \pm 12.2$ months. There were 45 patients with lesion in $\mathrm{C} 4-\mathrm{C} 5,87$ patients with lesion in $\mathrm{C} 5-\mathrm{C} 6$, and 49 patients with lesion in C6-C7. There were 32 patients in the noncorrection group and 149 patients in the correction group. There were only two patients who showed some degree of radiographic changes in adjacent discs, and these patients belonged to the correction group. Fusion status was found to be uncertain in one and three patients in the noncorrection and correction groups, respectively. Other patients achieved radiographic fusion. No patient showed radiographic pseudarthrosis.

On radiographic evaluation, the assessment of intraobserver and interobserver reliabilities showed excellent agreement between the measurements for segmental angle, C2-C7 angle, T1 slope, and C2-C7 SVA, indicating that all the measurements were reliable (Table 1). Patients' parameters from demographic, radiographic, and clinical data were summarized and compared (Table 2), and the results showed that there was no significant difference between the two groups before surgery $(P>0.05)$.

The postoperative data of the two groups are listed in Table 3. The segmental angle in the correction group

Table I Intraobserver reproducibility and interobserver reliability using intraclass correlation coefficient

\begin{tabular}{l|l|l}
\hline & Intraobserver & Interobserver \\
\hline Segmental angle & 0.84 & 0.81 \\
C2-C7 angle & 0.90 & 0.86 \\
TI slope & 0.88 & 0.83 \\
C2-C7 SVA & 0.82 & 0.79 \\
\hline
\end{tabular}

Notes: The intraclass coefficient value of $<0.40$ indicates poor, $0.40-0.75$ indicates fair or good, and $0.75-1.00$ indicates excellent reliability.

Abbreviation: SVA, sagittal vertical axis. 
Table 2 Demographic and clinical data in patients before singlelevel ACDF surgery

\begin{tabular}{|c|c|c|c|}
\hline & $\begin{array}{l}\text { Noncorrection } \\
\text { group }\end{array}$ & $\begin{array}{l}\text { Correction } \\
\text { group }\end{array}$ & $P$-value \\
\hline Number of patients & 32 & 149 & \\
\hline Age (years) & $51.0 \pm 8.9$ & $48.9 \pm 10.4$ & 0.29 \\
\hline \multicolumn{4}{|l|}{ Gender } \\
\hline Male & 17 & 82 & 0.84 \\
\hline Female & 15 & 67 & \\
\hline \multicolumn{4}{|l|}{ Diagnosis } \\
\hline Radiculopathy & 21 & 103 & 0.68 \\
\hline Myelopathy & 11 & 46 & \\
\hline $\begin{array}{l}\text { Duration of symptoms } \\
\text { (months) }\end{array}$ & $21.6 \pm 11.2$ & $24.1 \pm 12.8$ & 0.31 \\
\hline \multicolumn{4}{|l|}{ Lesion location } \\
\hline C4-C5 & 7 & 38 & 0.82 \\
\hline $\mathrm{C} 5-\mathrm{C} 6$ & 17 & 70 & \\
\hline C6-C7 & 8 & 41 & \\
\hline Segmental angle $\left({ }^{\circ}\right)$ & $-3.2 \pm 0.7$ & $-3.1 \pm 0.6$ & 0.41 \\
\hline $\mathrm{C} 2-\mathrm{C} 7$ angle $\left({ }^{\circ}\right)$ & $12.1 \pm 8.5$ & $12.3 \pm 7.9$ & 0.90 \\
\hline TI slope $\left(^{\circ}\right)$ & $26.1 \pm 4.5$ & $25.7 \pm 5.8$ & $0.7 \mathrm{I}$ \\
\hline C2-C7 SVA (mm) & $22.5 \pm 10.3$ & $23.3 \pm 12.2$ & 0.73 \\
\hline Preoperative NDI & $21.5 \pm 5.4$ & $21.2 \pm 6.1$ & 0.84 \\
\hline Preoperative VAS neck & $5.5 \pm 1.1$ & $5.3 \pm 1.2$ & 0.51 \\
\hline Preoperative VAS arm & $5.7 \pm 1.6$ & $5.8 \pm 1.4$ & 0.78 \\
\hline
\end{tabular}

Abbreviations: ACDF, anterior cervical discectomy and fusion; NDI, Neck Disability Index; SVA, sagittal vertical axis.

was $4.3^{\circ} \pm 0.6^{\circ}$, and it is significantly higher than that in the noncorrection group $(P<0.01)$, which is $-2.0^{\circ} \pm 0.4^{\circ}$. Similarly, the $\mathrm{C} 2-\mathrm{C} 7$ angle in the correction group is significantly higher than that in the noncorrection group, and the difference is statistically significant $\left(17.1^{\circ} \pm 3.4^{\circ}\right.$ vs $\left.13.4^{\circ} \pm 3.2^{\circ}, P<0.01\right)$. The $\mathrm{C} 2-\mathrm{C} 7 \mathrm{SVA}$ in the correction group is $16.3 \pm 10.2 \mathrm{~mm}$ and in the noncorrection group is $20.5 \pm 9.3 \mathrm{~mm}$, and the difference between the two groups is statistically significant $(P=0.03)$. However, no significant difference was shown in T1 slope, postoperative NDI or postoperative VAS between the two groups $(P>0.05)$.

Table 3 Postoperative data in patients with single-level ACDF surgery

\begin{tabular}{l|l|l|l}
\hline & $\begin{array}{l}\text { Noncorrection } \\
\text { group }\end{array}$ & $\begin{array}{l}\text { Correction } \\
\text { group }\end{array}$ & P-value \\
\hline Number of patients & 32 & 149 & \\
Segmental angle $\left(^{\circ}\right)$ & $-2.0 \pm 0.4$ & $4.3 \pm 0.6$ & $<0.01$ \\
C2-C7 angle $\left({ }^{\circ}\right)$ & $13.4 \pm 3.2$ & $17.1 \pm 3.4$ & $<0.01$ \\
TI slope $\left({ }^{\circ}\right)$ & $25.8 \pm 4.2$ & $25.9 \pm 5.6$ & 0.92 \\
C2-C7 SVA (mm) & $20.5 \pm 9.3$ & $16.3 \pm 10.2$ & 0.03 \\
Postoperative NDI & $12.2 \pm 3.1$ & $10.6 \pm 3.3$ & 0.16 \\
Postoperative VAS neck & $2.3 \pm 0.7$ & $2.1 \pm 0.6$ & 0.27 \\
Postoperative VAS arm & $2.3 \pm 0.3$ & $2.4 \pm 0.4$ & 0.40 \\
\hline
\end{tabular}

Abbreviations: ACDF, anterior cervical discectomy and fusion; NDI, Neck Disability Index; SVA, sagittal vertical axis.
In the correction group, the segmental angle changed from $-3.1 \pm 0.6$ to $4.3^{\circ} \pm 0.6^{\circ}$, the $\mathrm{C} 2-\mathrm{C} 7$ angle increased from $12.3 \pm 7.9$ to $17.1^{\circ} \pm 3.4^{\circ}$, and the $\mathrm{C} 2-\mathrm{C} 7 \mathrm{SVA}$ decreased from $23.3 \pm 12.2$ to $16.3 \pm 10.2 \mathrm{~mm}$. These changes were statistically significant. However, the preoperative T1 slope was $25.7^{\circ} \pm 5.8^{\circ}$, and the postoperative value was $25.9^{\circ} \pm 5.6^{\circ}$. There was no significant difference between the two values.

Pearson correlation analyses were further conducted to determine a possible quantitative relationship between changes in segmental angle and other alignment parameters. The results showed that changes in segmental angle were positively correlated with changes in $\mathrm{C} 2-\mathrm{C} 7$ angle $(r=0.27$, $P<0.01)$ and negatively correlated with changes in $\mathrm{C} 2-\mathrm{C} 7$ SVA $(r=-0.39, P<0.01$, Figure 2$)$.

\section{Discussion}

To the best of our knowledge, there are few studies that reported the effect of correction segmental alignment on the surgical outcomes. In the current study, we only included patients with segmental kyphosis and found that patients with kyphosis correction showed larger $\mathrm{C} 2-\mathrm{C} 7$ angle and lower C2-C7 SVA in comparison with those without satisfactory correction. Besides, changes in segmental angle were positively correlated with changes in $\mathrm{C} 2-\mathrm{C} 7$ angle and negatively correlated with changes in $\mathrm{C} 2-\mathrm{C} 7 \mathrm{SVA}$. Based on these results, we think that segmental alignment is important for maintaining the overall cervical sagittal balance; however, we cannot demonstrate that the correction of segmental alignment is associated with better recovery in clinical outcomes.

In previous studies, cervical sagittal alignment was considered to be correlated with clinical outcomes. ${ }^{15,16}$ For example, Fujiwara et a ${ }^{17}$ investigated 57 patients with cervical myelopathy and demonstrated that the maintenance of good sagittal balance as evaluated by the C2-C7 SVA is important for the recovery of cervical spine function. However, the radiographic cervical sagittal malalignment was not negatively correlated with axial neck pain. Tang et al ${ }^{18}$ analyzed 113 patients who received multilevel posterior cervical fusion and reported that $\mathrm{C} 2-\mathrm{C} 7 \mathrm{SVA}$ positively correlated with NDI scores and negatively correlated with Short Form-36 physical component scores. In this study, we only included patients with segmental kyphosis and the patients with good correction of segmental kyphosis showed a lower NDI and VAS in neck in comparison with those without good correction, but the difference is not statistically significant. There is a possibility that the correction of segmental kyphosis may change the whole cervical alignment and indirectly affect the clinical outcomes. However, 

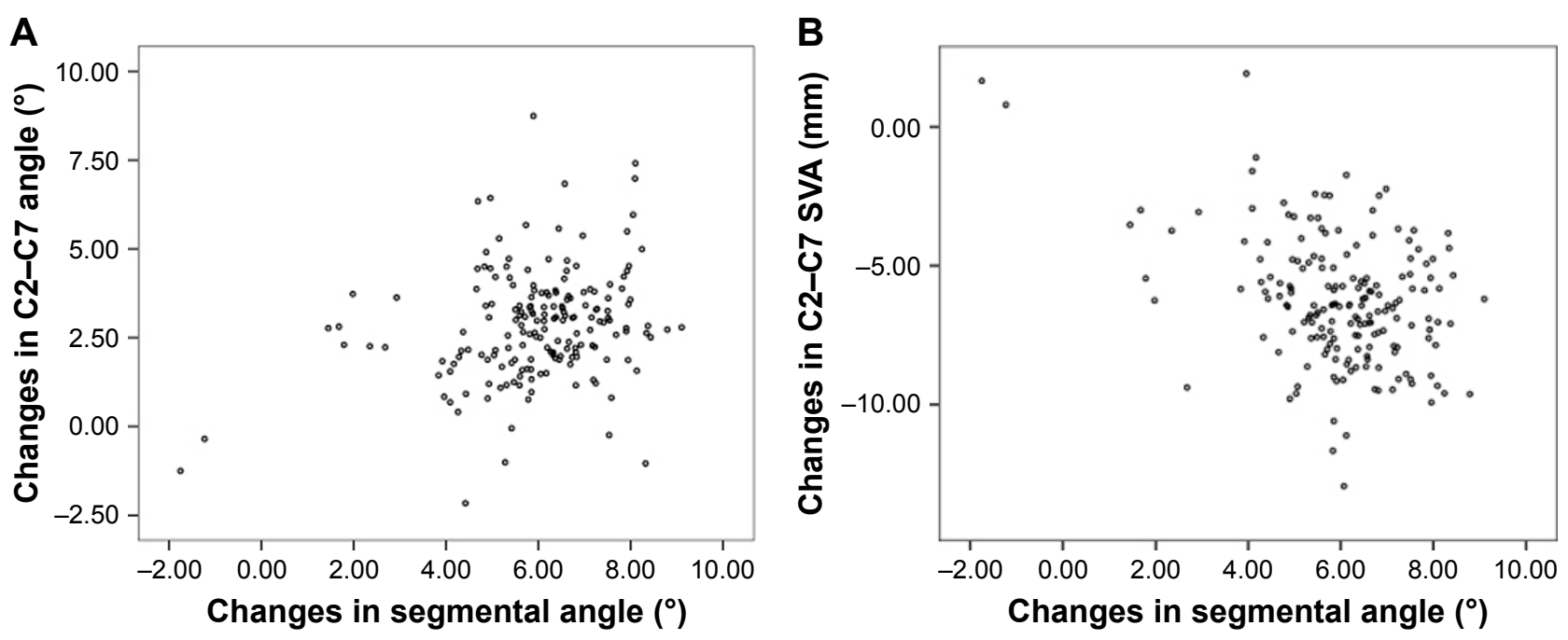

Figure 2 Correlations between the changes in segmental angle and changes in C2-C7 angle (A) as well as changes in C2-C7 SVA (B). Abbreviation: SVA, sagittal vertical axis.

this hypothesis requires a further study with a larger sample size to demonstrate it.

We further analyzed the association between segmental angle and cervical alignment, and the results showed that changes in segmental angle were positively correlated with changes in $\mathrm{C} 2-\mathrm{C} 7$ angle and negatively correlated with changes in C2-C7 SVA. After the correction of segmental kyphosis, it seems that patients had a more lordotic cervical spine and, at the same time, the SVA moved backward.

A previous study by Jeon et $\mathrm{al}^{19}$ included 33 patients who underwent three or more level ACDF for cervical stenosis, cervical degenerative disorder, or ossification of the posterior longitudinal ligament and concluded that multilevel ACDF did not significantly change the postoperative cervical alignment and thus may not significantly affect cervical alignment or clinical outcomes. A significant difference of their study from ours is the objective patients. We only included patients with segmental kyphosis, who had malalignment in the cervical spine. Surgical correction of these particular patients may make a difference in the outcomes.

However, attention should be paid to the methods to correct segmental kyphosis. Some authors considered that the shape of allografts may play an important role. Allografts can be categorized roughly into lordotic and parallel types. However, in a randomized clinical study by Villavicencio et al, ${ }^{20}$ the authors showed that the use of lordotically shaped allografts does not increase cervical segmental sagittal alignment in comparison with the parallelly shaped ones. In addition, cage subsidence was common in patients treated without the plate. ${ }^{21,22}$ The addition of an anterior plate system was considered to reduce the problem that the height tended to return gradually toward preoperative value. ${ }^{23}$ On the basis of our general practice, we recommended that the restoration of disc height in the index level is essential to correct segmental angle. However, risk factors for progressive cage subsidence, such as endplate excessive resection and oversized cage insertion with excessive distraction, should also be avoided during surgery. ${ }^{23,24}$

There are several limitations in the present study. First, this study only analyzed NDI and VAS and other functional outcome measurements, such as Short Form-36 and mean health-related quality of life were not evaluated because of the retrospective study design. Besides, this study did not conclude what is the exact amount of segmental angle that every patient requires to benefit the whole cervical alignment. We also do not certain if excessive lordotic angle will affect biomechanics negatively. Finally, we only included patients with single-level segmental kyphosis and our results may not be applicable to those with multi level cervical disorder or those without segmental kyphosis.

\section{Conclusion}

Surgical correction of segmental kyphosis in single-level cervical surgery contributed to balanced cervical alignment in comparison with those without satisfactory correction. Changes in segmental angle were positively correlated with changes in $\mathrm{C} 2-\mathrm{C} 7$ angle and negatively correlated with changes in C2-C7 SVA. However, we cannot demonstrate that the correction of segmental alignment is associated with a better recovery in clinical outcomes.

\section{Acknowledgment}

The present study was supported by a nonfinancial project from the Key Project of Medical Research of Hebei Province (no 20180458). 


\section{Disclosure}

The authors report no conflicts of interest in this work.

\section{References}

1. Holly LT, Matz PG, Anderson PA, et al. Functional outcomes assessment for cervical degenerative disease. J Neurosurg Spine. 2009;11(2): 238-244.

2. Alvin MD, Qureshi S, Klineberg E, et al. Cervical degenerative disease: systematic review of economic analyses. Spine. 2014;39(22 Suppl 1): S53-S64.

3. Schroeder GD, Kurd MF, Millhouse PW, Vaccaro AR, Hilibrand AS. Performing an Anterior Cervical Discectomy and Fusion. Clin Spine Surg. 2016;29(5):186-190.

4. Angevine PD, Zivin JG, Mccormick PC. Cost-effectiveness of singlelevel anterior cervical discectomy and fusion for cervical spondylosis. Spine. 2005;30(17):1989-1997.

5. Tamai K, Terai H, Suzuki A, et al. Anterior cervical discectomy and fusion provides better surgical outcomes than posterior laminoplasty in elderly patients with C3-4 level myelopathy. Spine. 2017;42(8): $548-555$.

6. Hirai T, Yoshii T, Arai Y, et al. A comparative study of anterior decompression with fusion and posterior decompression with laminoplasty for the treatment of cervical spondylotic myelopathy patients with large anterior compression of the spinal cord. Clin Spine Surg. 2017; 30(8):E1137-E1142.

7. Kong LD, Zhang YZ, Wang F, Kong FL, Ding WY, Shen Y. Radiographic restoration of sagittal spinopelvic alignment after posterior lumbar interbody fusion in degenerative spondylolisthesis. Clin Spine Surg. 2016;29(2):E87-E92.

8. Wu WJ, Jiang LS, Liang Y, Dai LY. Cage subsidence does not, but cervical lordosis improvement does affect the long-term results of anterior cervical fusion with stand-alone cage for degenerative cervical disc disease: a retrospective study. Eur Spine J. 2012;21(7):1374-1382.

9. Hyun SJ, Kim KJ, Jahng TA, Kim HJ. Relationship between T1 slope and cervical alignment following multilevel posterior cervical fusion surgery: impact of T1 slope minus cervical lordosis. Spine. 2016;41(7): E396-E402.

10. Sun Y, Yu K, Wang H, Shen Y, Kong L, Zhang J. Diagnosis and treatment of hidden lesions in "mild" cervical spondylotic myelopathy patients with apparent symptoms. Medicine. 2017;96(30):e7623.

11. Vernon H, Mior S. The neck disability index: a study of reliability and validity. J Manipulative Physiol Ther. 1991;14(7):409-415.

12. Kwon WK, Kim PS, Ahn SY, et al. Analysis of associating factors with C2-7 sagittal vertical axis after two-level anterior cervical fusion: comparison between plate augmentation and stand-alone cages. Spine. 2017;42(5):318-325.
13. Chung JY, Kim SK, Jung ST, Lee KB. Clinical adjacent-segment pathology after anterior cervical discectomy and fusion: results after a minimum of 10-year follow-up. Spine J. 2014;14(10):2290-2298.

14. Brantigan JW. Pseudarthrosis rate after allograft posterior lumbar interbody fusion with pedicle screw and plate fixation. Spine. 1994; 19(11):1271-1279.

15. Iyer S, Nemani VM, Nguyen J, et al. Impact of cervical sagittal alignment parameters on neck disability. Spine. 2016;41(5):371-377.

16. Moon BJ, Choi KH, Yun C, Ha Y. Cross-sectional study of neck pain and cervical sagittal alignment in air force pilots. Aerosp Med Hum Perform. 2015;86(5):445-451.

17. Fujiwara H, Oda T, Makino T, Moriguchi Y, Yonenobu K, Kaito T. Impact of cervical sagittal alignment on axial neck pain and healthrelated quality of life after cervical laminoplasty in patients with cervical spondylotic myelopathy or ossification of the posterior longitudinal ligament: a prospective comparative study. Clin Spine Surg. 2018;31(4): E245-E251.

18. Tang JA, Scheer JK, Smith JS, et al. The impact of standing regional cervical sagittal alignment on outcomes in posterior cervical fusion surgery. Neurosurgery. 2015;76(Suppl 1):S14-S21.

19. Jeon SI, Hyun SJ, Han S, et al. Relationship between cervical sagittal alignment and patient outcomes after anterior cervical fusion surgery involving 3 or more levels. World Neurosurg. 2018;113:e548-e554.

20. Villavicencio AT, Babuska JM, Ashton A, et al. Prospective, randomized, double-blind clinical study evaluating the correlation of clinical outcomes and cervical sagittal alignment. Neurosurgery. 2011;68(5): 1309-1316.

21. Barsa P, Suchomel P. Factors affecting sagittal malalignment due to cage subsidence in standalone cage assisted anterior cervical fusion. Eur Spine J. 2007;16(9):1395-1400.

22. Tomé-Bermejo F, Morales-Valencia JA, Moreno-Pérez J, et al. Degenerative cervical disc disease: long-term changes in sagittal alignment and their clinical implications after cervical interbody fusion cage subsidence: a prospective study with standalone lordotic tantalum cages. Clin Spine Surg. 2017;30(5):E648-E655.

23. Fujibayashi S, Neo M, Nakamura T. Stand-alone interbody cage versus anterior cervical plate for treatment of cervical disc herniation: sequential changes in cage subsidence. J Clin Neurosci. 2008;15(9):1017-1022.

24. Noordhoek I, Koning MT, Jacobs WCH, Vleggeert-Lankamp CLA. Incidence and clinical relevance of cage subsidence in anterior cervical discectomy and fusion: a systematic review. Acta Neurochir. 2018; 160(4):873-880.
Therapeutics and Clinical Risk Management

\section{Publish your work in this journal}

Therapeutics and Clinical Risk Management is an international, peerreviewed journal of clinical therapeutics and risk management, focusing on concise rapid reporting of clinical studies in all therapeutic areas, outcomes, safety, and programs for the effective, safe, and sustained use of medicines. This journal is indexed on PubMed Central, CAS,

\section{Dovepress}

EMBase, Scopus and the Elsevier Bibliographic databases. The manuscript management system is completely online and includes a very quick and fair peer-review system, which is all easy to use. Visit $\mathrm{http}: / / \mathrm{www}$.dovepress.com/testimonials.php to read real quotes from published authors. 